\title{
As Conferências Públicas Nacionais e a formação da agenda de políticas públicas do Governo Federal (2003-2010)
}

\author{
Viviane Petinelli \\ Programa de Pós-Graduação em Ciência Política \\ Universidade Federal de Minas Gerais
}

Resumo: Este artigo examina a incorporação de deliberações das conferências nacionais na agenda de políticas públicas do governo federal e sugere aspectos que afetam a capacidade desses espaços de influenciar esse processo. A hipótese é de que o grau de incorporação de cada conferência, isto é, sua capacidade inclusiva, varia de acordo com a política pública debatida, na medida em que cada política possui finalidade própria, envolve um tipo distinto de sociedade civil e compete a uma instituição com centralidade política diferente. Para testar essa proposição, o artigo compara as conferências nacionais de aquicultura e pesca, de políticas para mulheres e de políticas de promoção da igualdade racial. Os resultados encontrados corroboram a suposição deste trabalho na medida em que atestam que conferências de política pública distintas apresentam capacidade inclusiva diferente.

Palavras-chave: Conferências Públicas Nacionais, participação da sociedade civil, deliberações, capacidade inclusiva, agenda de políticas públicas

\begin{abstract}
This paper examines the incorporation of the deliberations of the national conferences into the policy agenda of the Brazilian federal government and suggests aspects that affect the capacity of these public spaces to influence this process. The hypothesis is that the degree of incorporation of each conference, i.e., its inclusive capacity, varies according to the nature of the public policy debated, given that each policy has its own purpose, involves a distinct type of civil society and is formulated by different public institutions. To test this proposition, the article compares the national conferences of aquaculture and fishery, of women and of racial policy. The results corroborate the assumption that conferences of distinct public policies have different inclusive capacity.
\end{abstract}

Keywords: National Conferences of Public Policy, civil society participation, deliberation, inclusive capacity, policy agenda 
PETINELLI, V. As Conferências Públicas Nacionais e a formação da agenda de políticas...

\section{Introdução}

Em documento publicado no dia 15 de Setembro de 2009, o Instituto de Pesquisa Econômica e Aplicada (IPEA), ao se referir à estrutura participativa criada pelo governo Lula a partir de 2003, constatou um avanço na participação social no Brasil, notadamente por meio de conferências públicas, como resposta do Estado aos reclamos da sociedade civil por maior controle social e ampliação do espaço político. A publicação Brasil em Desenvolvimento: Estado, Planejamento e Políticas Públicas (IPEA, 2009) assinalou que, sob o marco do projeto democráticoparticipativo priorizado por este governo, as conferências tornaram-se um símbolo da democracia participativa no país em função da frequência que têm sido realizadas, do expressivo contingente de pessoas e movimentos sociais que têm envolvido e dos novos temas que têm introduzido no debate político.

Por outro lado, a pesquisa do IPEA mostrou que ainda faltam mecanismos legais que assegurem a incorporação e a execução das deliberações aprovadas nesses espaços pelo governo federal. Segundo o estudo, a capacidade das conferências nacionais de influenciar a formação da agenda de políticas públicas do Governo Federal deriva do vínculo da conferência com marcos legais, ainda que isso não assegure a aplicação das decisões em sua totalidade. Sob esse prisma, somente as conferências que tratam de políticas públicas constitucionais, como as de Saúde, de Direitos da Criança e do Adolescente e as de Assistência Social, apresentariam força política suficiente para incluir as diretrizes nelas aprovadas na agenda governamental.

Os registros do IPEA chamam atenção para as dificuldades encontradas pelas conferências de influenciar a formação da agenda política do governo federal. Por se tratar de um tema muito recente para a literatura brasileira, muito pouco ainda foi publicado a esse respeito. A análise que mais se aproxima nesse sentido é a de Santos e Pogrebinschi (2010), na qual os autores examinam e mensuram a influência das deliberações das conferências realizadas a partir de 1988 sobre as iniciativas de proposições de leis no Congresso Nacional entre 1988 e 2008.

Deste modo, o objetivo deste trabalho é iniciar este debate. Afinal, se é verdade que somente as conferências nacionais de políticas públicas constitucionais apresentam capacidade suficiente de influenciar a formação da agenda de políticas públicas do governo federal, para que as demais conferências têm servido? Se não, em que medida as diretrizes produzidas nas conferências nacionais, não regulamentadas por lei (consultivas), têm influenciado a formação da agenda de políticas públicas do governo federal? Indo além, quais aspectos podem afetar essa capacidade das conferências de influenciar as decisões políticas?

Responder a essas questões constitui-se a finalidade deste artigo. Busca-se aqui (1) analisar se, e em que medida, as deliberações de conferências nacionais 
consultivas têm sido incorporadas na agenda de políticas públicas do governo federal e (2) sugerir porque o grau de incorporação dessas deliberações varia entre conferências de política pública distinta. Ao longo do trabalho, utilizamos a expressão "capacidade inclusiva da conferência" para nos referir à capacidade da mesma influenciar as decisões do governo federal em relação às políticas públicas. Na ausência de uma definição mensurável desse termo, a capacidade inclusiva foi medida pelo grau de incorporação das deliberações produzidas nesses espaços e obtida a partir de análise documental.

A hipótese que norteia esta pesquisa é a de que a capacidade inclusiva das conferências varia de acordo com a política pública nela debatida, na medida em que cada política possui finalidade própria - social, administrativa ou econômica -, envolve um tipo distinto de sociedade civil - com base em movimentos sociais e entidades civis e de base profissional e empresarial - e é formulada e implementada por uma instituição com centralidade política diferente - observada em termos de recursos orçamentários recebidos pelo Ministério.

Para empreender a análise, foram examinadas as conferências nacionais de três temas: Aquicultura e Pesca, Políticas para Mulheres e Políticas de Promoção da Igualdade Racial, escolhidas a partir de três critérios. Primeiro, todas são organizadas por instituições criadas pelo governo Lula em janeiro de 2003 e vinculadas à estrutura da Presidência da República. Segundo, as três tratam de políticas públicas que nunca haviam sido debatidas em espaços com participação de atores estatais e da sociedade civil anteriormente. Por fim, elas discutem políticas distintas, o que nos permite compará-las para testar a hipótese deste trabalho.

Para aferir a incorporação das propostas produzidas nessas conferências na agenda do governo federal, o estudo analisa, comparativamente, os relatórios finais da $1^{a}$ e da $2^{a}$ Conferência Nacional de cada área, disponíveis nos sites das respectivas instituições.

O trabalho está dividido em três partes: na primeira, apresentamos um panorama geral das conferências nacionais realizadas no Brasil a partir de 1988, explicitando seu universo temático, sua estrutura institucional e a dinâmica participativa e deliberativa nesses espaços. Na segunda seção, descrevemos as conferências nacionais de Aquicultura e Pesca, de Políticas para Mulheres e de Políticas de Promoção da Igualdade Racial, apontando para suas diferenças, sobretudo, em relação à finalidade da política pública que debatem, ao tipo de sociedade civil que envolvem e à centralidade política da instituição à qual estão vinculadas. Na última seção, testamos se, e em que medida, a capacidade inclusiva das conferências, isto é, sua capacidade de influenciar a agenda de políticas públicas do governo federal, varia entre conferências que tratam de política pública distinta e em que sentido se dá essa variação. 
PETINELLI, V. As Conferências Públicas Nacionais e a formação da agenda de políticas...

\section{As Conferências Públicas Nacionais: 1988 - 2010.}

As Conferências Públicas constituem espaços públicos de participação e deliberação de diretrizes gerais de políticas públicas, organizadas tematicamente e que envolvem governo e sociedade civil (SILVA, 2009; MORONI, 2005; SANTOS e POGREBINSCHI, 2010). Elas foram criadas no governo Vargas, pela Lei $n^{\circ} 378$, de 13 de Janeiro de 1937, com o objetivo de facilitar o conhecimento do Governo Federal acerca das atividades relativas à saúde e de orientá-lo na execução dos serviços locais de saúde. Nesta lei, ficou definido que os encontros seriam convocados pelo Presidente da República e contariam com a participação de representantes do governo dos três níveis da Federação e de representantes dos grupos sociais relacionados à área tema da Conferência (SAYD, VIEIRA JUNIOR e VELANDIA, 1998). Desde então, as conferências têm sido convocadas por decreto presidencial e têm sido realizadas pelos Ministérios ou Secretarias da área, com o apoio do Conselho a eles vinculado. Nos dois governos Lula, esses espaços passaram a contar também com o suporte da Secretaria Geral da Presidência da República (SGPR) tanto na organização dos encontros, como no diálogo com o Governo Federal. Assim, as conferências se tornaram as principais instâncias de proposição de novas diretrizes de políticas públicas para compor o Plano Plurianual de Ação (PPA) do governo e de monitoramento e avaliação das ações governamentais nas três esferas da Federação.

As conferências são financiadas pela Administração Pública através de seus Ministérios e Secretarias Municipais e Estaduais e podem ser patrocinadas pelo setor privado. Além disso, esses espaços são, em regra, precedidos por etapas municipais e/ou estaduais ou regionais. Os resultados agregados das deliberações ocorridas nestas etapas são objetos de deliberação na conferência nacional, na qual participam delegados das etapas anteriores e da qual resulta um documento final contendo diretrizes para a formulação de políticas públicas da área tema da conferência (SANTOS e POGREBINSCHI, 2010).

$O$ instrumento que materializa esses espaços é o regimento interno, elaborado, na maior parte dos casos, pelos Conselhos da área, com a participação da Secretaria ou do Ministério ao qual está vinculado. Nele, o desenho das conferências é delineado pela definição dos objetivos do encontro, dos eixos temáticos a serem debatidos, das etapas e das datas de realização dos debates, do número e da composição de atores estatais e não-estatais (delegados) por unidade da Federação; da dinâmica de deliberação das propostas, e das orientações gerais para o encaminhamento das propostas aprovadas em cada encontro para a comissão organizadora da conferência seguinte. Em todos os níveis da federação, este documento deve passar pelo crivo da plenária da conferência, que pode aprová-lo na íntegra, aprová-lo com mudanças ou rejeitá-lo. No último caso, os 
delegados devem formular e aprovar outro regimento antes de dar continuidade aos trabalhos.

Desde sua criação até 2010, já foram realizadas 111 conferências nacionais e centenas de milhares de conferências intermediárias, nas esferas municipais e estaduais. Do total de encontros nacionais, 9 aconteceram entre 1941 e 1988 - 11 delas referentes ao tema saúde e 1 de Ciência e Tecnologia; e as demais 99 conferências foram organizadas pós 1988 (BRASIL, 2011). O Quadro 1 apresenta os temas de políticas públicas debatidos em conferências nacionais, por instituição e ano de realização, entre 1988 e 2010.

\section{Quadro 1: Conferências Nacionais por instituição e ano de realização (1988 a 2010)}

\begin{tabular}{|c|c|c|c|}
\hline & Tema da Conferência & Instituição & Ano de realização \\
\hline 1 & Aprendizagem Profissional & Ministério do Trabalho e Emprego & 2008 \\
\hline 2 & Aquicultura e Pesca & Ministério da Pesca e Aquicultura & 2003/2006/2009 \\
\hline 3 & Arranjos Produtivos Locais & $\begin{array}{l}\text { Ministério do Desenvolvimento, } \\
\text { Indústria e Comércio Exterior }\end{array}$ & $2004 / 2005 / 2007$ \\
\hline 4 & Assistência Social & Ministério do Desenvolvimento Social & $\begin{array}{l}1995 / 1997 / 1999 / 2001 \\
2003 / 2005 / 2007 / 2009\end{array}$ \\
\hline 5 & Cidades & Ministério das Cidades & $2003 / 2005 / 2007 / 2010$ \\
\hline 6 & Ciência e Tecnologia & Ministério de Ciência e Tecnologia & $2001 / 2005 / 2010$ \\
\hline 7 & $\begin{array}{l}\text { Ciência, Tecnologia e } \\
\text { Inovação em Saúde } \\
\end{array}$ & Ministério da Saúde & $1994 / 2004$ \\
\hline 8 & Comunicação & Ministério das Comunicações & 2009 \\
\hline 9 & $\begin{array}{l}\text { Comunidades Brasileiras } \\
\text { no Exterior }\end{array}$ & Ministério das Relações Exteriores & $2008 / 2009$ \\
\hline 10 & Cultura & Ministério da Cultura & $2005 / 2010$ \\
\hline 11 & $\begin{array}{l}\text { Defesa Civil e Assistência } \\
\text { Humanitária }\end{array}$ & Ministério da Integração Nacional & 2010 \\
\hline 12 & $\begin{array}{l}\text { Desenvolvimento Rural, } \\
\text { Sustentável e Solidário }\end{array}$ & Ministério do Desenvolvimento Rural & 2008 \\
\hline 13 & $\begin{array}{l}\text { Direitos da Criança e do } \\
\text { Adolescente }\end{array}$ & Secretaria Especial Direitos Humanos & $\begin{array}{l}1997 / 1999 / 2002 / 2003 / \\
2005 / 2007 / 2009\end{array}$ \\
\hline 14 & $\begin{array}{l}\text { Direitos da Pessoa com } \\
\text { Deficiência }\end{array}$ & Secretaria Especial Direitos Humanos & $2006 / 2008$ \\
\hline 15 & Direitos da Pessoa Idosa & Secretaria Especial Direitos Humanos & $2006 / 2009$ \\
\hline 16 & Direitos Humanos & Secretaria Especial Direitos Humanos & $\begin{array}{l}1996 / 1997 / 1998 / 1999 / \\
2000 / 2001 / 2002 / 2003 / \\
2004 / 2006 / 2008\end{array}$ \\
\hline 17 & Economia Solidária & Ministério do Trabalho e Emprego & $2006 / 2010$ \\
\hline 18 & Educação & Ministério da Educação & 2010 \\
\hline
\end{tabular}


PETINELLI, V. As Conferências Públicas Nacionais e a formação da agenda de políticas...

\begin{tabular}{|c|c|c|c|}
\hline 19 & Educação Básica & Ministério da Educação & 2008 \\
\hline 20 & $\begin{array}{l}\text { Educação Escolar } \\
\text { Indígena }\end{array}$ & Ministério da Educação & 2009 \\
\hline 21 & $\begin{array}{l}\text { Educação Profissional e } \\
\text { Tecnológica }\end{array}$ & Ministério da Educação & 2006 \\
\hline 22 & Esporte & Ministério do Esporte & $2004 / 2006 / 2010$ \\
\hline 23 & $\begin{array}{l}\text { Gays, Lésbicas, } \\
\text { Bissexuais, Travestis e } \\
\text { Transexuais }\end{array}$ & Secretaria Especial Direitos Humanos & 2008 \\
\hline 24 & $\begin{array}{l}\text { Gestão do Trabalho e da } \\
\text { Educação na Saúde }\end{array}$ & Ministério da Saúde & $1994 / 2006$ \\
\hline 25 & $\begin{array}{l}\text { Infanto-Juvenil pelo Meio } \\
\text { Ambiente }\end{array}$ & Ministério do Meio Ambiente & $2003 / 2006 / 2009$ \\
\hline 26 & Juventude & Secretaria Geral Presidência Republica & 2008 \\
\hline 27 & $\begin{array}{l}\text { Medicamentos e } \\
\text { Assistência Farmacêutica }\end{array}$ & Ministério da Saúde & 2003 \\
\hline 28 & Meio Ambiente & Ministério do Meio Ambiente & 2003/2005/2008 \\
\hline 29 & $\begin{array}{l}\text { Políticas Públicas para as } \\
\text { Mulheres }\end{array}$ & Secretaria Especial Políticas Mulheres & 2004/2007 \\
\hline 30 & Povos Indígenas & Secretaria Especial Direitos Humanos & 2006 \\
\hline 31 & $\begin{array}{l}\text { Promoção da Igualdade } \\
\text { Racial }\end{array}$ & $\begin{array}{l}\text { Secretaria Especial Promoção Igualdade } \\
\text { Racial }\end{array}$ & $2005 / 2009$ \\
\hline 32 & $\begin{array}{l}\text { Recursos Humanos da } \\
\text { Administração Pública } \\
\text { Federal }\end{array}$ & Planejamento, Orçamento e Gestão & 2009 \\
\hline 33 & Saúde & Ministério da Saúde & $\begin{array}{l}1992 / 1996 / 2000 / 2003 / \\
2007\end{array}$ \\
\hline 34 & Saúde Ambiental & Ministério da Saúde & 2009 \\
\hline 35 & Saúde Bucal & Ministério da Saúde & $1993 / 2004$ \\
\hline 36 & Saúde do Trabalhador & Ministério da Saúde & $1994 / 2005$ \\
\hline 37 & Saúde Indígena & Ministério da Saúde & $1993 / 2001 / 2006$ \\
\hline 38 & Saúde Mental & Ministério da Saúde & $1992 / 2001 / 2010$ \\
\hline 39 & $\begin{array}{l}\text { Segurança Alimentar e } \\
\text { Nutricional }\end{array}$ & Ministério do Desenvolvimento Social & $1994 / 2004 / 2007$ \\
\hline 40 & Segurança Pública & Ministério da Justiça & 2009 \\
\hline
\end{tabular}

Fonte: Secretaria Geral da Presidência da República (BRASIL, 2011).

Pelo Quadro 1, observa-se que, entre 1988 e 2010, 40 políticas públicas distintas foram debatidas em conferências nacionais e intermediárias (municipais, regionais e estaduais). Destas, 27 foram organizadas entre 1988 e 2002 e debateram políticas de Saúde, Assistência Social, Direitos Humanos, Direitos da Criança e do Adolescente e Segurança Alimentar e Nutricional, e as outras 72 Conferências, que correspondem a 65\% do total, ocorreram entre 2003 e 2010, durante os dois governos Lula. 
A diferença no número e na proporção de encontros realizados no governo Lula se deve ao fato de que este governo priorizou uma gestão mais democrática e participativa e, com tal objetivo, buscou construir um novo pacto com a sociedade civil por meio da criação e institucionalização de novos espaços participativos. Neste sentido, o governo constituiu a Secretaria Nacional de Articulação Social, vinculada à Secretaria Geral da Presidência da República (SGPR), para desenvolver esses espaços, e ampliou as atribuições da SGPR, que se tornou responsável por promover a articulação entre governo e entidades civis e de implementar instrumentos de consulta e de participação popular de interesse do Poder Executivo. Dentre os espaços participativos fomentados, as conferências de políticas públicas e os fóruns de discussão do Plano Plurianual (PPA) tornaram-se os mais importantes na construção do relacionamento entre governo e sociedade civil. Os primeiros foram constituídos para auxiliar a elaboração do PPA 2004-2007, enquanto as Conferências têm sido organizadas, desde então, para discutir e deliberar propostas de políticas públicas.

Dos 24 Ministérios e 8 Secretarias da Presidência com status de Ministério, 21 deles já realizaram, pelo menos, 1 conferência. Dentre estes, a Secretaria Especial de Direitos Humanos constitui-se a recordista, com 24 conferências nacionais realizadas pós 88 em 6 temas distintos. Em seguida, vem o Ministério da Saúde, com 21 ocorrências em 9 temas distintos. Considerando, porém, todo o período desde a instituição das conferências em 1937, a saúde se apresenta como o tema recordista, com 32 encontros nacionais entre 1937 e 2010. Em seguida, vem o Ministério do Desenvolvimento Social e do Meio Ambiente, com 11 e 6 conferências, respectivamente, em 2 temas distintos. Os demais Ministérios e Secretarias Especiais realizaram entre 1 e 4 conferências nacionais de 1988 a 2010 (Quadro 1).

As diferenças em relação à quantidade e à diversidade temática das conferências realizadas por cada Ministério parecem resultar de características próprias da organização de cada área de política pública, assim como se observa para as instituições participativas, como os Conselhos de Política (TATAGIBA e TEIXEIRA, 2008). A saúde, recordista em número de encontros e em diversidade de temas discutidos em conferências, consiste em uma política constitucional, cujo desenho foi construído, historicamente, com a participação de profissionais e de usuários, desde as primeiras décadas do século XX. De forma semelhante, a política de direitos humanos, a segunda com maior número de conferências realizadas e de temas debatidos, foi construída com a participação de atores sociais, nacional e internacionalmente relevantes, em fóruns, conferências e convenções mundiais, organizadas a partir dos anos de 1980.

Tendo isso em vista e diante do universo de conferências já realizadas, optouse, neste trabalho, por analisar os encontros nacionais de aquicultura e pesca, de 
PETINELLI, V. As Conferências Públicas Nacionais e a formação da agenda de políticas...

políticas para mulheres e de políticas de promoção da igualdade racial devido a três razões principais. Primeiro, devido que a $1^{\text {a }}$ conferência de cada área foi realizada no primeiro mandato do governo Lula (2003-2006). Segundo, por serem políticas públicas incorporadas como políticas de governo em 2003, através da criação de uma secretaria especial, com status de Ministério, vinculada à SGPR, para cada uma delas. Por último, por debaterem políticas públicas distintas, que se diferenciam ou se assemelham em relação a sua finalidade, ao tipo de sociedade civil que envolvem e ao vínculo institucional que apresentam. Isso permite testar a proposição deste trabalho de que conferências de política pública distinta apresentam capacidade inclusiva diferente. Esses pontos estão descritos na seção seguinte.

\section{As Conferências Nacionais de Aquicultura e Pesca, de Políticas para Mulheres e de Políticas de Promoção da Igualdade Racial}

As Conferências Nacionais de Aquicultura e Pesca, de Políticas para Mulheres e de Políticas de Promoção da Igualdade Racial são realizadas por iniciativa do Ministério da Pesca e Aquicultura (MPA), da Secretaria Especial de Políticas para Mulheres (SPM) e da Secretaria Especial de Políticas de Promoção da Igualdade Racial (SEPPIR), respectivamente, e contam com o apoio do Conselho Nacional da área e da Secretaria Geral da Presidência da República. Sendo assim, todas as despesas referentes ao encontro ficam a cargo da instituição que o promove, que deve cumpri-las por meio de recursos orçamentários próprios, aprovados na Lei Orçamentária Anual do ano anterior (LOA) e repassados pela Casa Civil.

O MPA, a SPM e a SEPPIR, assim como os demais órgãos do Poder Executivo, recebem recursos para duas finalidades: (1) para o custeio da máquina administrativa e implementação de projetos e (2) para a execução de programas da instituição. Os primeiros são calculados a partir das despesas administrativas de pessoal esperadas para o ano seguinte. Os recursos para programas, por sua vez, requerem um esforço político por parte do Ministro, na medida em que dependem de autorização da Comissão de Orçamento da LOA e de inclusão de rubrica nesta lei para tal finalidade. Deste modo, cada Ministério e Secretaria Especial obtêm montantes distintos de recursos, que variam, entre outros, com seu tamanho institucional, com a centralidade de sua política pública para o Governo Federal e com sua capacidade de influenciar politicamente as decisões orçamentárias. A Tabela 1 apresenta o total de recursos orçamentários recebidos pelo MPA, pela SPM e pela SEPPIR entre 2003 e 2010, enquanto a Tabela 2 mostra a proporção desses recursos recebida para execução de programas desses ministérios. 
OPINIÃO PÚBLICA, Campinas, vol. 17, no 1, Junho, 2011 , p.228-250

Tabela 1

Recursos Orçamentários recebidos pelo MPA, SPM e SEPPIR entre 2003 e 2010 (R\$ 1,00)

\begin{tabular}{|c|c|c|c|}
\hline Ano/ Instituição & \multicolumn{1}{l|}{ MPA } & \multicolumn{1}{l|}{ SEPPIR } & SPM \\
\hline $\mathbf{2 0 0 3}$ & 12.342 .000 & SI & 24.135 .000 \\
\hline $\mathbf{2 0 0 4}$ & 89.071 .000 & 17.252 .000 & 26.192 .000 \\
\hline $\mathbf{2 0 0 5}$ & 75.952 .114 & 14.058 .109 & 17.052 .414 \\
\hline $\mathbf{2 0 0 6}$ & 76.253 .988 & 18.430 .401 & 17.383 .848 \\
\hline $\mathbf{2 0 0 7}$ & 113.982 .394 & 18.121 .100 & 24.757 .394 \\
\hline $\mathbf{2 0 0 8}$ & 92.571 .970 & 14.641 .561 & 37.136 .241 \\
\hline $\mathbf{2 0 0 9}$ & 371.896 .664 & 15.893 .450 & 29.670 .828 \\
\hline $\mathbf{2 0 1 0}$ & 799.430 .483 & 20.534 .450 & 61.038 .900 \\
\hline
\end{tabular}

Fonte: formulação própria a partir de dados obtidos no Portal do Orçamento. Disponível em: <www.senado.gov.br>. Acesso em: [08 abr. 2011]; e no site do Ministério do Planejamento. Disponível em: <www.planejamento.gov.br>. Acesso em: [08 abr. 2011]. Legenda: SI - sem informação.

Tabela 2

Total de recursos recebidos para execução de programas por órgão entre 2003 e 2010 (R\$ 1,00)

\begin{tabular}{|l|l|l|l|l|}
\hline Órgão & $\begin{array}{l}\text { Total de } \\
\text { Recursos } \\
\text { recebidos por } \\
\text { órgão }\end{array}$ & $\begin{array}{l}\text { Recursos recebidos } \\
\text { para execução de } \\
\text { programas }\end{array}$ & $\begin{array}{l}\text { \% total de recursos } \\
\text { recebidos para } \\
\text { programas }\end{array}$ & $\begin{array}{l}\text { Média de } \\
\text { programas na } \\
\text { LOA por ano }\end{array}$ \\
\hline MPA & 1.990 .261 .079 & 1.452 .890 .588 & $73 \%$ & 6 \\
\hline SEPPIR & 184.182 .242 & 116.034 .812 & $63 \%$ & 3 \\
\hline SPM & 333.696 .522 & 220.239 .705 & $66 \%$ & 4 \\
\hline
\end{tabular}

Fonte: formulação própria a partir de dados do site Disponível em:

<http://www.senado.gov.br/portal/page/portal/orcamento_senado>

Como mostra a Tabela 1, o MPA recebeu o maior montante de recursos orçamentários de 2003 a 2010, sendo este, em média, 6 vezes maior que o da SPM e 10 vezes maior que o da SEPPIR. Esta última obteve o menor repasse de recursos durante quase todo o período analisado, salvo no ano de 2006, quando a SPM recebeu o montante mais baixo, de $\mathrm{R} \$ 17.383 .848,00$, segundo a Tabela 2 . Do total de recursos recebidos por instituição, parcela significativa foi repassada para a implementação dos programas dessas instituições que receberam rubrica na LOA. No caso do MPA, $73 \%$ dos recursos foram repassados para a execução de programas do Ministério, enquanto que $63 \%$ e $66 \%$ do total de recursos recebidos pela SEPPIR e pela SPM, respectivamente, foram destinados à execução de programas dessas instituições. Os recursos repassados ao MPA para programas 
PETINELLI, V. As Conferências Públicas Nacionais e a formação da agenda de políticas...

foram aplicados em 6 programas distintos, em média, durante 2003 e 2010, ao passo que os recursos para programas encaminhados para a SEPPIR e para a SPM foram destinados à execução de 3 e 4 programas, respectivamente, nos 8 anos de governo Lula.

Dado que o MPA recebeu o maior montante de recursos orçamentários por ano e em todo o período analisado e que incluiu o maior número de programas na LOA, comparativamente às outras duas instituições, espera-se que ele apresente maior capacidade inclusiva. Essa suposição se justifica na medida em que a incorporação das propostas deliberadas nas conferências se dá, sobretudo, em programas do Ministério. Como o MPA apresenta maior número de programas incluídos na LOA, em média, durante 2003 e 2010, e a eles foi destinada parcela maior de recursos, a incorporação de diretrizes aprovadas nas conferências da área torna-se mais fácil, em termos econômicos, e, como decorrência, sua capacidade inclusiva tende a ser maior.

A $1^{\text {a }}$ Conferência Nacional de Aquicultura e Pesca foi realizada de 25 a 27 de Novembro de 2003. Seu objetivo foi construir um Plano Estratégico de Desenvolvimento da Aquicultura e da Pesca. No ano seguinte, foi organizada a $1^{\text {a }}$ Conferência Nacional de Políticas para Mulheres, entre 15 e 17 de Julho. Este encontro buscou propor diretrizes para a formulação do I Plano Nacional de Políticas para Mulheres (PNM I) e avaliou as ações, até então, desenvolvidas pela SPM. Com objetivos semelhantes, quais sejam, o de formular um Plano Nacional de Políticas de Promoção da Igualdade Racial e avaliar a atuação da SEPPIR na promoção da igualdade racial, foi realizada, de 30 de Junho a 02 de Julho de 2005, a $1^{\text {a }}$ Conferência Nacional desta área.

A $2^{a}$ Conferência Nacional de cada área deu continuidade aos trabalhos iniciados no primeiro encontro. No caso da Aquicultura e Pesca, o $2^{\circ}$ encontro ocorreu entre 14 e 16 de Março de 2006 e teve como finalidade consolidar a Política Nacional de Desenvolvimento do setor e avaliar a incorporação das deliberações produzidas no $1^{\circ}$ encontro na agenda do MPA ${ }^{1}$. Do mesmo modo, a $2^{a}$ Conferência Nacional de Políticas para Mulheres e de Promoção da Igualdade Racial buscaram consolidar e avaliar a implementação do Plano Nacional da área. Estas foram realizadas de 18 a 20 de Agosto de 2007 e de 25 a 28 de Junho de 2009, respectivamente.

Os primeiros encontros nacionais de Mulheres e de Igualdade Racial foram antecedidos por conferências municipais, enquanto o de Aquicultura e Pesca foi precedido somente por conferências estaduais. Foram realizadas mais de 2.000

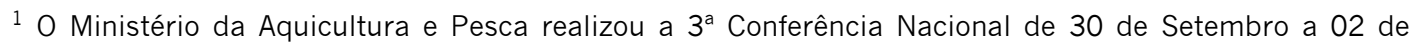
Outubro de 2009, cujo tema foi: "Consolidação de uma Política de Estado para o Desenvolvimento Sustentável da Aquicultura e Pesca". Nela, os delegados avaliaram a Política Nacional de desenvolvimento do setor e acrescentaram diretrizes e ações do governo para que a Aquicultura e Pesca se tornem políticas permanentes, ou seja, políticas de Estado.
} 
conferências municipais, 26 encontros estaduais e 1 encontro no Distrito Federal para debater políticas para Mulheres; cerca de 1.300 encontros municipais, 26 estaduais e 1 no Distrito Federal para discutir políticas de Promoção da lgualdade Racial; e 26 conferências estaduais e 1 no Distrito Federal sobre Aquicultura e Pesca.

Este formato foi mantido para o $2^{\circ}$ encontro de Aquicultura e Pesca em 2006 e de políticas para mulheres em 2007, mas foi alterado em relação à política de Igualdade Racial, cujas conferências foram iniciadas a nível estadual e não a nível municipal, como no primeiro ano de encontros ${ }^{2}$. Nos dois anos de realização de conferências, portanto, foram realizados cerca de 4.000 encontros para debater Políticas para Mulheres, 1.400 conferências de lgualdade Racial e 54 conferências de Aquicultura e Pesca (Tabela 3).

Os 4.000 encontros de Políticas para Mulheres reuniram centenas de milhares de pessoas nas etapas municipais e estaduais, totalizando cerca de 240 mil pessoas envolvidas nos dois anos de encontros. Deste total, cerca de 4 mil delegados participaram das Conferências Nacionais, dos quais 2.000 (50\%), em média, representavam entidades e associações civis e movimentos sociais da área (BRASIL, 2009a). De forma semelhante, as conferências de políticas de promoção da igualdade racial contaram com a participação de mais de 140 mil pessoas. Destas, 4 mil participaram dos encontros nacionais, sendo 2.400 (60\%) delas, na média dos encontros, representantes de movimentos sociais e associações e entidades civis (BRASIL, 2009c). Já os encontros de Aquicultura e Pesca envolveram aproximadamente 40 mil pessoas. Dos cerca de 4 mil participantes dos encontros nacionais, $50 \%$, em média, representavam associações de profissionais e grupos empresariais vinculados ao setor (BRASIL, 2009e), conforme mostra a Tabela 3.

\footnotetext{
${ }^{2}$ Segundo a coordenadora geral da Conferência Estadual de Minas Gerais, o principal motivo para essa mudança foi a incapacidade financeira de grande parte dos municípios de investir na realização do encontro. Neste contexto, optou-se por iniciar as discussões a nível estadual e não nos municípios, como em 2005.
} 
PETINELLI, V. As Conferências Públicas Nacionais e a formação da agenda de políticas...

Tabela 3

Número total aproximado de Conferências e de participantes por área

\begin{tabular}{|c|c|c|c|}
\hline Área & $\begin{array}{c}\text { Total } \\
\text { aproximado de } \\
\text { Conferências }\end{array}$ & $\begin{array}{c}\text { Total } \\
\text { aproximado de } \\
\text { participantes }\end{array}$ & Composição da participação \\
\hline $\begin{array}{c}\text { Aquicultura e } \\
\text { Pesca }\end{array}$ & 54 & 40 mil & $\begin{array}{c}50 \% \text { atores estatais e } 50 \% \\
\text { representantes de associações } \\
\text { profissionais e de empresários }\end{array}$ \\
\hline $\begin{array}{c}\text { Igualdade } \\
\text { Racial }\end{array}$ & 1.400 & 150 mil & $\begin{array}{c}60 \% \text { atores estatais e } 40 \% \\
\text { representantes de movimentos sociais } \\
\text { entidades civis }\end{array}$ \\
\hline Mulheres & 4.000 & 240 mil & $\begin{array}{c}50 \% \text { atores estatais e } 50 \% \\
\text { representantes de movimentos } \\
\text { sociais e entidades civis }\end{array}$ \\
\hline
\end{tabular}

Fonte: Relatório final da $1^{\text {a }}$ Conferência Nacional de Aquicultura e Pesca, da $1^{\text {a }}$ Conferência Nacional de Políticas para Mulheres e da $1^{\text {a }}$ Conferência Nacional de Políticas de Promoção da Igualdade Racial. Disponível em: <www.presidencia.gov.br>. Acesso em: [08 abr. 2011]. (BRASIL (b), (d), (f), 2009).

A adoção de uma prática participativa e deliberativa distinta pelas instituições responsáveis por essas conferências - mais descentralizada para os encontros de Mulheres e de Promoção da Igualdade Racial e mais centralizada para as conferências de Aquicultura e Pesca - assim como a diferença em termos de número e composição dos participantes dessas áreas parecem se justificar pelo fato de que esses encontros envolvem uma sociedade civil com história e organização distinta.

No que diz respeito à história, as conferências de políticas para mulheres ${ }^{3} \mathrm{e}$ de promoção da igualdade racial $^{4}$ contam com a participação de uma sociedade

\footnotetext{
3 As políticas públicas para mulheres foram incorporadas ao Estado nos anos 80 com a criação de delegacias especializadas na defesa das mulheres e do Conselho Nacional de Políticas para Mulheres (CNDM) em 1985, vinculado ao Ministério da Justiça (PINTO, 2003). No entanto, entre 1989 e 1994 , o CNDM ficou desestruturado e sem autonomia administrativa e financeira. Nos dois governos Fernando Henrique Cardoso, pouco se fez a esse respeito e o Conselho continuou a ser um órgão subordinado, administrativa e financeiramente, ao Ministro da Justiça. Somente em 2002, quando foi criada a Secretaria dos Direitos da Mulher (SEDIM), esta situação modificou-se e a questão das mulheres tornouse política de governo.

${ }^{4}$ A questão racial foi incorporada ao Estado com a instituição da Fundação Cultural Palmares (FCP) em 1988 para comemorar os 100 anos de abolição da escravidão no país. Este organismo federal foi vinculado ao Ministério da Cultura e tinha como objetivo promover e preservar a influência negra na sociedade brasileira. Ademais, a Constituição Federal de 1988 reconheceu, de forma inédita, o racismo e o preconceito racial como fenômenos presentes na sociedade brasileira, sustentando a necessidade de combatê-los. Como decorrência, Entre 1990 e 1995, as centrais sindicais e os principais sindicatos passaram a incluir a temática racial em sua pauta de reivindicações, o que refletiu, sobretudo, no aparecimento de órgãos específicos do tema nessas instituições. Dessa mobilização resultou a criação do Instituto Interamericano pela Igualdade Racial (Inspir). Além disso, a mobilização do Movimento Negro contribuiu para a instituição do Grupo de Trabalho Interministerial de Valorização da População Negra, vinculado ao Ministério da Justiça, responsável pela proposição de ações de combate à discriminação racial (GARCIA, 2008).
} 
civil articulada, autônoma, experiente na luta por seus direitos, e amplamente difundida em território nacional; o que não se verifica para a área de Aquicultura e Pesca ${ }^{5}$, que conta com a participação de uma sociedade civil de formação ainda incipiente, menos difundida territorialmente e com capacidade de mobilização menor que daquelas.

Em relação à organização, as conferências de Aquicultura e Pesca envolvem representantes de associações de profissionais e de grupos empresariais, que são orientados para valores materiais e buscam intervenções setorializadas por parte do governo. Já os encontros de mulheres e de promoção da igualdade racial, por tratarem de questões de gênero e étnico-raciais respectivamente, contam com a participação de representantes de movimentos sociais e associações e entidades civis, orientados, sobretudo, para valores identitários e que lutam por um objeto coletivo.

Como as conferências de Aquicultura e Pesca envolvem grupos empresariais, espera-se que elas apresentem maior capacidade inclusiva, comparativamente às de política para mulheres e de promoção da igualdade racial. Isso se justifica na medida em que o Brasil, até o século passado, era caracterizado pelo alto grau de permeabilidade aos interesses privados dominantes nos processos decisórios desenvolvidos no âmbito do Executivo. Durante quase todo o século XX, a formação da agenda de políticas públicas do governo federal foi constrangida por um sistema corporativo de interesses no interior do Estado, que institucionalizou uma prática de negociação com os grupos econômicos, transformando o executivo em arena privilegiada para o encaminhamento das demandas empresariais (DINIZ, 1992). Mediante essa herança, acredita-se que as conferências de aquicultura e pesca, que contam com a participação de grupos de interesse econômico, apresentem capacidade inclusiva maior, dado que a incorporação das diretrizes aprovadas nesses espaços torna-se mais fácil, em termos políticos, pela presença desses grupos.

A participação dos representantes da sociedade civil, em todas as conferências, foi realizada em Grupos de Trabalho (GTs), mediante a proposição de diretrizes e a avaliação das políticas formadoras da agenda do governo. A $1^{\text {a }}$ Conferência Nacional de Aquicultura e Pesca foi dividida em 7 eixos temáticos, a $1^{\text {a }}$ de Políticas para Mulheres em 5, e a $1^{\text {a }}$ de Promoção da lgualdade Racial, em 12. De igual forma, as $2^{\text {as }}$ conferências dessas áreas abordaram esses assuntos e

\footnotetext{
5 Até a redemocratização, em 1985, a área de Aquicultura e Pesca esteve vinculada à SUDEPE e, com sua extinção nesse mesmo ano, esse setor passou a ser de competência do IBAMA. Em 1990, porém, a MP 150/1990 extinguiu essa atribuição deste órgão e a aquicultura e a pesca deixaram de ser políticas públicas. Somente em 1998, pela MP 1450, esses setores foram reincorporados ao Estado, com a criação de um Departamento de Aquicultura e Pesca na estrutura do Ministério do Abastecimento, Pecuária e Agricultura.
} 
PETINELLI, V. As Conferências Públicas Nacionais e a formação da agenda de políticas...

acrescentaram o eixo de direito à moradia e à terra, debatidos nos encontros de políticas para mulheres e promoção da igualdade racial, e de enfrentamento da desigualdade social, debatido nas conferências de políticas para mulheres. 0 Quadro 2 explicita os eixos temáticos por área e por conferência.

\section{Quadro 2}

\section{Eixos temáticos das Conferências Nacionais de Aquicultura e Pesca, de Políticas para Mulheres e de Promoção da Igualdade Racial}

\begin{tabular}{|c|c|c|c|}
\hline Conferência & $\begin{array}{c}\text { Aquicultura e } \\
\text { Pesca }\end{array}$ & Igualdade Racial & Mulheres \\
\hline $1^{a}$ & $\begin{array}{l}\text { 1. Participação } \\
\text { 2. Ordenamento } \\
\text { Pesqueiro } \\
\text { 3. Estruturação } \\
\text { setor } \\
\text { 4. Estruturação } \\
\text { Pesca } \\
\text { 5. Políticas Sociais } \\
\text { para setor } \\
\text { 6. Políticas de } \\
\text { crédito } \\
\text { 7. Política de } \\
\text { desenvolviment } \\
\text { o tecnológico } \\
\text { 8. Produção e } \\
\text { Fome Zero }\end{array}$ & $\begin{array}{l}\text { 1. Trabalho/Desenvolvimento } \\
\text { 2. Educação } \\
\text { 3. Saúde } \\
\text { 4. Diversidade Cultural } \\
\text { 5. Direitos Humanos e } \\
\text { Segurança Pública } \\
\text { 6. Comunidades Quilombolas } \\
\text { 7. Povos Indígenas } \\
\text { 8. Juventude } \\
\text { 9. Mulheres } \\
\text { 10. Política Internacional } \\
\text { 11. Religiões } \\
\text { 12. Fortalecimento de } \\
\text { ONGS anti-racismo }\end{array}$ & $\begin{array}{l}\text { 1. Enfrentamento da } \\
\text { pobreza } \\
\text { 2. Superação da } \\
\text { violência } \\
\text { 3. Promoção do bem- } \\
\text { estar } \\
\text { 4. Efetivação dos direitos } \\
\text { humanos } \\
\text { 5. Desenvolvimento de } \\
\text { políticas de educação, } \\
\text { cultura, comunicação } \\
\text { e produção do } \\
\text { conhecimento }\end{array}$ \\
\hline $2^{a}$ & $\begin{array}{l}\text { 1. Desenvolvimento } \\
\text { Pesca Industrial } \\
\text { 2. Desenvolvimento } \\
\text { Pesca Artesanal } \\
\text { 3. Desenvolvimento } \\
\text { Aquicultura } \\
\text { 4. Apoio a Cadeia } \\
\text { Produtiva }\end{array}$ & $\begin{array}{l}\text { 1. Educação } \\
\text { 2. Cultura } \\
\text { 3. Controle Social } \\
\text { 4. Saúde } \\
\text { 5. Terra } \\
\text { 6. Segurança e Justiça } \\
\text { 7. Trabalho } \\
\text { 8. Política Nacional } \\
\text { 9. Política Internacional }\end{array}$ & $\begin{array}{l}\text { 1. Autonomia/lgualdade. } \\
\text { 2. Educação } \\
\text { 3. Saúde } \\
\text { 4. Enfrentamento da } \\
\text { violência } \\
\text { 5. Participação no poder } \\
\text { 6. Desenvolvimento } \\
\text { econômico } \\
\text { 7. Direito moradia, terra } \\
\text { 8. Cultura } \\
\text { 9. Enfrentamento } \\
\text { racismo } \\
\text { 10. Enfrentamento } \\
\text { desigualdade } \\
\text { 11. Monitoramento Plano }\end{array}$ \\
\hline
\end{tabular}

Fonte: formulação própria a partir de dados da Secretaria Geral da Presidência da República (BRASIL, 2011). 
Como mostra o Quadro 2, as conferências de Aquicultura e Pesca debateram, em maior medida, questões de ordem econômica. No $1^{\circ}$ encontro, foram estabelecidos 3 eixos de um total de 7 para debater o desenvolvimento do setor e, no $2^{\circ}$, os 4 temas discutiram o desenvolvimento da aquicultura, da maricultura, da pesca industrial e da pesca artesanal. Os encontros de políticas para mulheres, por sua vez, discutiram, em maior medida, questões sociais, orientadas para a melhoria das condições de vida das mulheres. Os 5 eixos temáticos da $1^{\text {a }}$ Conferência Nacional de Política para Mulheres e 8 dos 11 temas tratados no $2^{\circ}$ encontro debateram essas questões. Somente os eixos participação no poder, desenvolvimento econômico e monitoramento do plano não debateram propostas de cunho social. Do mesmo modo, as duas Conferências Nacionais de Políticas de Promoção da Igualdade Racial discutiram, em sua maioria, assuntos sociais, voltados para a promoção socioeconômica da população negra e indígena. No $1^{\circ}$ encontro, dos 12 temas discutidos, 10 trataram de matérias desse tema - com exceção dos eixos: política internacional e fortalecimento de ONGs; enquanto que, na $2^{a}$ conferência, 6 dos 9 eixos disseram respeito a questões análogas.

Os assuntos dos eixos temáticos das conferências refletem a finalidade da política pública debatida nos encontros. As conferências de Aquicultura e Pesca, por representarem um setor econômico, debateram, em grande medida, assuntos propriamente econômicos; ao passo que os encontros de Mulheres e de lgualdade Racial, que tratam de políticas identitárias, de reconhecimento ${ }^{6}$, cuja finalidade é social, discutiram propostas de promoção socioeconômica desses grupos.

As políticas públicas de cunho social são, em sua maioria, intersetoriais e transversais e têm como finalidade a redistribuição de benefícios sociais de modo a diminuir as desigualdades estruturais produzidas pelo desenvolvimento socioeconômico. Como tal, elas demandam maior esforço político e menor estrutura administrativa, maior coordenação entre as instituições públicas e mais recursos orçamentários. Ademais, essas políticas não geram retorno financeiro, em termos de arrecadação de impostos, de investimentos e de produção, para o governo e para o país. As políticas com finalidade econômica, por outro lado, são, geralmente, setoriais e voltadas para grupos econômicos específicos. Como tal, elas tendem a demandar menor esforço político, menor estrutura administrativa e menor coordenação política, assim como a depender de menos recursos orçamentários para sua execução. Deste modo, espera-se que conferências que tratam de assuntos de cunho econômico, como as de Aquicultura e Pesca, apresentem capacidade inclusiva maior que as que debatem temas propriamente sociais.

De modo geral, portanto, o que se observa é que as conferências de aquicultura e pesca, de políticas para mulheres e de políticas de promoção da igualdade racial debatem políticas públicas com finalidade distinta que envolvem uma sociedade civil com história e organização distinta e estão vinculadas a

\footnotetext{
${ }^{6}$ Para a discussão sobre políticas de reconhecimento e políticas redistributivas, ver, entre outros, FRASER, N.; HONNETH, A.; 2003.
} 
PETINELLI, V. As Conferências Públicas Nacionais e a formação da agenda de políticas...

ministérios com centralidade política diferente na estrutura do governo federal. Enquanto as conferências de aquicultura e pesca debatem uma política cuja finalidade é econômica, envolvem uma sociedade civil de base profissional e empresarial e são realizadas por um Ministério com maior centralidade política (interpretada em termos de recursos orçamentários), os encontros de políticas para mulheres e de promoção da igualdade racial tratam de políticas de cunho social, envolvem uma sociedade civil com tradição de luta por meio de movimentos sociais e são realizadas por Secretarias Especiais cujo orçamento é consideravelmente menor que o do MPA. As características que distinguem essas conferências nacionais estão sistematizadas no Quadro 3.

\section{Quadro 3}

Características das Conferências Nacionais de Aquicultura e Pesca, de Políticas para Mulheres e de Políticas de Promoção da Igualdade Racial

\begin{tabular}{|c|c|c|c|}
\hline Características & $\begin{array}{c}\text { Aquicultura e } \\
\text { Pesca }\end{array}$ & Igualdade Racial & Mulheres \\
\hline $\begin{array}{c}\text { Centralidade política, } \\
\text { medida em termos de } \\
\text { recursos orçamentários } \\
\text { (total em R\$1,00, 2003 a } \\
\text { 2010) }\end{array}$ & 1.990 .261 .079 & 184.182 .242 & 333.696 .522 \\
\hline $\begin{array}{c}\text { História e tipo } \\
\text { organização da }\end{array}$ & $\begin{array}{c}\text { Formação recente } \\
\text { Baseada em } \\
\text { associações de } \\
\text { trabalhadores } \\
\text { grupos } \\
\text { empresariais }\end{array}$ & $\begin{array}{c}\text { Tradição de } \\
\text { participação } \\
\text { Baseada em } \\
\text { movimentos sociais }\end{array}$ & $\begin{array}{c}\text { Tradição de } \\
\text { participação } \\
\text { Baseada em } \\
\text { movimentos sociais }\end{array}$ \\
\hline $\begin{array}{c}\text { Finalidade da Política } \\
\text { Pública }\end{array}$ & $\begin{array}{c}\text { Econômica } \\
\text { Sconocial }\end{array}$ & Social \\
\hline
\end{tabular}

Fonte: formulação própria a partir da Tabela 2 e do Quadro 2.

Resta aferir, então, a capacidade inclusiva dessas conferências e examinar se, e em que medida, ela varia por política pública e conforme suas diferenças e semelhanças quanto à centralidade da instituição sede do encontro, ao tipo de sociedade civil envolvida e à finalidade da política. 


\section{Aferindo a capacidade inclusiva das Conferências Nacionais de Aquicultura e Pesca, de Políticas para Mulheres e de Políticas de Promoção da Igualdade Racial}

\section{A $1^{\text {a }}$ Conferência Nacional de Aquicultura e Pesca produziu 172 deliberações} nos 7 eixos temáticos supracitados (Quadro 2), ao passo que $01^{\circ}$ encontro de Políticas para Mulheres deliberou 78 propostas em 5 eixos e a $1^{\text {a }}$ Conferência de Promoção da Igualdade Racial, 1.048 resoluções em 12 temas (Tabela 4). Essas propostas, discutidas e aprovadas nos GTs e por maioria simples dos delegados na Plenária final, foram englobadas em um único documento por uma comissão de relatoria, composta por representantes da sociedade civil e do governo, e encaminhadas para a instituição sede para análise e incorporação na agenda ${ }^{7}$.

\section{Tabela 4}

Número de Resoluções aprovadas por tema e ano de conferência

\begin{tabular}{|c|c|c|}
\hline Tema & $\begin{array}{c}\text { Total de Resoluções Aprovadas } \\
\text { na } \mathbf{1}^{\mathbf{a}} \text { Conferência }\end{array}$ & $\begin{array}{c}\text { Total de Resoluções } \\
\text { Aprovadas na 2 }\end{array}$ Conferência \\
\hline Aquicultura e Pesca & 172 & 249 \\
\hline Igualdade Racial & 1.048 & 761 \\
\hline Mulheres & 78 & 199 \\
\hline TOTAL & 1.298 & 1.209 \\
\hline
\end{tabular}

Fonte: Relatório final da $1^{\text {a }}$ Conferência Nacional de Aquicultura e Pesca, da $1^{\text {a }}$ Conferência Nacional de Políticas para Mulheres e da $1^{a}$ Conferência Nacional de Políticas de Promoção da Igualdade Racial. Disponível em: <www.presidencia.gov.br> (BRASIL, (b), (d), (f), 2009).

As $2^{\text {as }}$ conferências nacionais de cada área seguiram o mesmo formato participativo adotado no primeiro encontro. A avaliação das ações do governo federal foi realizada em GTs a partir de um documento-base com todas as propostas aprovadas na conferência anterior (Tabela 4). Com este documento em mãos, os delegados analisaram se a proposta foi ou não incluída pelo governo e propuseram alterações na forma e no conteúdo das mesmas, assim como novas ações de governo. O Quadro 4 apresenta o modelo de documento adotado nas $2^{\text {as }}$ conferências de políticas de promoção da igualdade racial para avaliar a incorporação das propostas aprovadas no primeiro encontro e discutir e propor novas ações de governo.

\footnotetext{
7 É importante atentar, porém, para o fato de que, embora o Estado seja o responsável pela convocação das conferências e pelos seus financiamentos, as decisões nelas produzidas não impõem, legalmente, nenhuma responsabilidade ao Estado, na medida em que são apenas consultivas.
} 
PETINELLI, V. As Conferências Públicas Nacionais e a formação da agenda de políticas...

\section{Quadro 4 \\ Modelo do Instrumental de Trabalho utilizado para discussão de propostas nos GTs das conferências de políticas de promoção da igualdade racial}

\begin{tabular}{|c|c|c|c|c|}
\hline Numero & Proposta & Política Implantada & Nova Redação & Observação \\
\hline 1 & $\times$ & $\times$ Sim & & \\
\hline
\end{tabular}

Fonte: Instrumental de Trabalho das $2^{a}$ Conferência Nacional de Promoção da Igualdade Racial.

As propostas não-incorporadas, segundo deliberação da maioria simples dos delegados de cada GT, assim como as novas propostas sugeridas e aprovadas nesses espaços, foram reunidas em um único documento, pela comissão de relatoria, para avaliação da plenária da conferência. Esta foi realizada no último dia do encontro e contou com a participação de todos os delegados. Na plenária, as propostas consideradas não-incluídas pelo governo e as novas propostas aprovadas nos GTs foram votadas. As deliberações aprovadas por maioria simples dos delegados - novas propostas e resoluções do $1^{\circ}$ encontro não-incorporadas à agenda governamental - foram, então, reunidas em um documento e encaminhadas para a instituição sede da conferência. No caso da Aquicultura e Pesca, o documento final da $2^{a}$ conferência nacional foi composto por 249 propostas de políticas públicas, o da $2^{a}$ conferência nacional de políticas para mulheres reuniu 199 resoluções, e o documento do $2^{\circ}$ encontro nacional de políticas de promoção da igualdade racial, 761 deliberações, como mostra a Tabela 4.

A partir das deliberações aprovadas na $1^{\text {a }}$ e na $2^{a}$ conferência de cada uma dessas áreas, foram construídos os bancos de dados para analisar a capacidade inclusiva desses espaços, aqui medida pelo grau de incorporação das propostas deliberadas nas conferências e inseridas, segundo avaliação dos delegados, na agenda do governo federal. A partir de comparação entre o documento final da $2^{a}$ conferência e o documento final da $1^{a}$, cada proposta foi, então, classificada pelo critério: incluída ou não-incluída na agenda. As resoluções inseridas na agenda, segundo avaliação dos delegados presentes, aparecem somente no $1^{\circ}$ documento, ao passo que as propostas não incorporadas pelo governo apareceram em ambos os documentos finais, mesmo que com alterações textuais. Às propostas não incluídas e contidas nos dois documentos, atribuiu-se valor 0 , e às propostas incorporadas e observadas somente no documento final da $1^{a}$ conferência, atribuiuse valor 1. A variável resultante desse processo foi denominada "capacidade inclusiva da conferência", proxy para a capacidade desses espaços de influenciar a formação da agenda de políticas públicas do governo federal.

Os Gráficos 1, 2 e 3 apresentam a capacidade inclusiva das conferências de Aquicultura e Pesca, Políticas para Mulheres e Promoção da Igualdade Racial, obtida a partir de comparação documental dos relatórios finais desses encontros. Segundo os dados, os encontros de aquicultura e pesca tiveram $55 \%$ de suas 
deliberações incluídas na agenda do governo federal entre a $1^{a}$ e a $2^{a}$ conferência da área, ao passo que os encontros de políticas para mulheres e de políticas de promoção da igualdade racial obtiveram $45 \%$ e $43 \%$ de inclusão, respectivamente.

\section{Gráfico 1}

Capacidade inclusiva das Conferências Nacionais de Aquicultura e Pesca

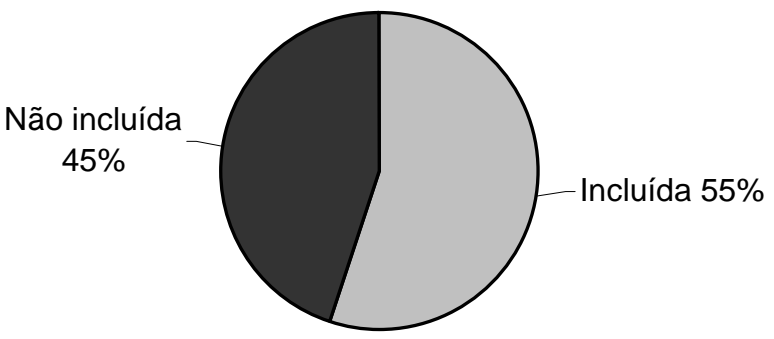

Fonte: Relatório final desta Conferência. Disponível em: <www.presidencia.gov.br>.

\section{Gráfico 2}

Capacidade inclusiva das Conferências Nacionais de Políticas para Mulheres

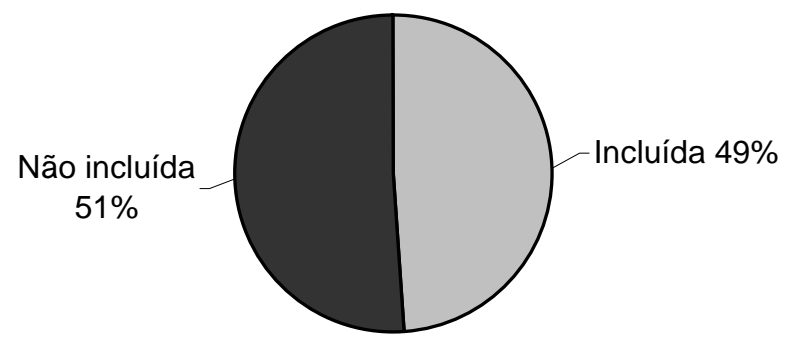

Fonte: Relatório final desta Conferência. Disponível em: <www.presidencia.gov.br>.

\section{Gráfico 3}

Capacidade inclusiva das Conferências Nacionais de Políticas de Promoção da Igualdade Racial

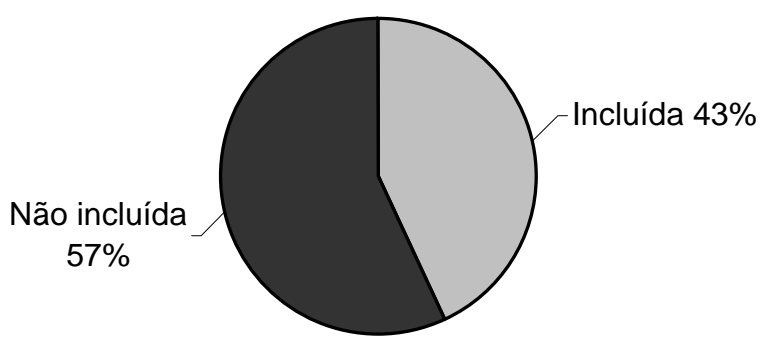

Fonte: Relatório final desta Conferência. Disponível em: <www.presidencia.gov.br>. 
PETINELLI, V. As Conferências Públicas Nacionais e a formação da agenda de políticas...

Resta aferir, então, a capacidade inclusiva dessas conferências e examinar se, e em que medida, ela varia por política pública e conforme suas diferenças e semelhanças no que diz respeito à centralidade da instituição sede do encontro, ao tipo de sociedade civil envolvida e à finalidade da política.

Esses resultados apresentam duas implicações no que concerne à proposta deste trabalho. A primeira é que o fato de uma conferência ser consultiva não significa, necessariamente, que ela não terá capacidade de influenciar a agenda governamental, como sugerido por estudos já desenvolvidos e citados na introdução deste trabalho (IPEA, 2009). Assim como as conferências deliberativas, as conferências consultivas, analisadas neste artigo, também se mostram capazes de influenciar, em alguma medida, a formação da agenda do governo federal. Isso se verifica pelo seu expressivo grau de incorporação de propostas pelo governo federal, (Gráficos 1, 2 e 3).

A segunda implicação diz respeito à própria capacidade inclusiva das conferências. As constatações acima corroboram a hipótese de que conferências de políticas públicas distintas apresentam capacidade inclusiva diferente.

Ademais, os resultados sugerem que essa capacidade de influenciar a agenda governamental tende a ser maior (1) quando a centralidade política da instituiçãosede da conferência (interpretada em termos de recursos orçamentários) é maior; (2) quando a conferência envolve a participação de grupos de interesse empresarial e (3) quando debatem políticas públicas cuja finalidade é econômica. Isso pode ser inferido na medida em que as conferências de aquicultura e pesca, que reúnem todas essas três características, apresentaram maior capacidade inclusiva (55\%) que os encontros de políticas para mulheres e de promoção da igualdade racial, cuja capacidade inclusiva encontrada $(45 \%$ e $43 \%$ respectivamente) e características (finalidade da política, história e organização da sociedade civil que envolvem e centralidade política da instituição-sede) são muito semelhantes (Quadro 3).

Desse modo, os resultados encontrados apontam (1) para os efeitos da realização de conferências sobre a agenda governamental e (2) para as diferenças na capacidade inclusiva de conferências de políticas públicas distintas. Além disso, as constatações sugerem que a finalidade da política, a história e o tipo de organização da sociedade civil e a centralidade política da instituição-sede impactam, em alguma medida, a capacidade inclusiva das conferências. Aferir o sentido e a magnitude desses efeitos constitui, assim, o desafio para as próximas pesquisas sobre o papel das conferências públicas nacionais na formação da agenda de políticas públicas do governo federal. 


\section{Considerações Finais}

Nos últimos 20 anos, o Brasil assistiu a uma explosão da participação social através de instituições e espaços públicos de participação e deliberação. Esse processo, que teve início no final dos anos 1980, com a redemocratização do país e a promulgação da Constituição Democrática de 1988, foi possível mediante os esforços teórico e prático de uma série de protagonistas sociais e políticos. Desde então, diversas práticas participativas, impulsionadas pela Constituição e pelos governos democráticos que se seguiram a ela - notadamente o governo Lula -, têm sido institucionalizadas de forma crescente. Tais práticas vão desde as mais tradicionais, como o referendo e o plebiscito, até as mais inovadoras, como as Conferências de Políticas Públicas.

O desafio desse artigo foi analisar uma dessas inovações, as Conferências Públicas, e aferir o grau incorporação das diretrizes aprovadas nesses espaços na agenda de políticas públicas do governo federal. Ademais, buscou-se sugerir aspectos que tendem a afetar a capacidade desses espaços de influenciar esse processo.

De maneira geral, é possível afirmar que as conferências públicas não apenas têm influenciado a formação da agenda de políticas públicas do governo federal, como também o têm feito de maneira relativamente eficiente, uma vez que parte expressiva das propostas aprovadas tem sido incorporada nos programas do governo federal.

Os achados dessa investigação mostram-se relevantes para o conjunto de estudos acerca do processo de formação da agenda das políticas públicas em áreas que realizam conferências públicas, pois adicionam conhecimentos a um tema ainda pouco explorado. No entanto, estamos cientes que o alcance empírico e teórico tem significativas limitações, pelo fato de termos analisado em conferências de apenas três temas distintos, que representam somente $5 \%$ do total de encontros já realizados. De todo modo, espera-se que os resultados aqui obtidos e as sugestões apresentadas sirvam de ponto de partida para novas pesquisas sobre o tema. 
PETINELLI, V. As Conferências Públicas Nacionais e a formação da agenda de políticas...

\section{Referências Bibliográficas}

BRASIL, República Federativa do. Secretaria Geral da Presidência da República.

Disponível em: <www.presidencia.gov.br>. Acesso em: [08 abr. 2011].

. (a), Secretaria Especial de Políticas para Mulheres (SPM). 2009. Disponível em: <www.presidencia.gov.br>. Acesso em: [jan. a dez. 2009].

(b), Secretaria Especial de Políticas para Mulheres. Relatório da I

Conferência Nacional de Políticas para as Mulheres. Disponível em:

<http://www.presidencia.gov.br/estrutura_presidencia/sepm/>. Acesso em: [jan. a dez. 2009].

. (c), Secretaria Especial de Políticas de Promoção da Igualdade Racial (SEPPIR). 2009. Disponível em: <www.presidencia.gov.br>. Acesso em: [jan. a dez. 2009].

. (d), Secretaria Especial de Políticas de Promoção da Igualdade Racial.

Relatório da I Conferência Nacional de Políticas de Promoção da Igualdade Racial.

Disponível em:

<http://www.presidencia.gov.br/estrutura_presidencia/seppir/publicacoes/> Acesso em: [jan. a dez. 2009].

. (e), Ministério da Pesca e Aquicultura (MPA). 2009. Disponível em:

<www.presidencia.gov.br>. Acesso em: [jan. a dez. 2009].

. (f), Ministério da Aquicultura e Pesca. Relatório da I Conferência Nacional de Aquicultura e Pesca. Disponível em:

<http://200.198.202.145/seap/conferencia/conferencia.htm>. Acesso em: [jan. a dez. 2009].

DINIZ, E. Neoliberalismo e corporativismo: as duas faces do poder. E Diniz - Revista Brasileira de Ciências Sociais, 1992.

FRASER, N.; HONNETH, A. Redistribution or Recognition: A Political-Philosophical Exchange. Rio de Janeiro: Verso, 2003.

IPEA, Instituto de Pesquisas Econômicas Aplicadas. 2009. Disponível em: $<w w w . i p e a . g o v . b r>$. Acesso em: [nov. e dez. 2009]. 
MORONI, J. A.; CICONELLO, A. Participação social no governo Lula. Avançamos? ABONG Associação Brasileira de Organizações Não Governamentais, 2005.

PINTO, C.R.J. Uma história do feminismo no Brasil. São Paulo: Fundação Perseu Abramo, 2003.

SANTOS, F. M.; POGREBINSCHI, T. Entre representação e participação: as conferências nacionais e o experimentalismo democrático brasileiro. Instituto Universitário de Pesquisas do Rio de Janeiro (IUPERJ): Projeto Pensando o Direito da Secretaria de Assuntos Legislativos do Ministério da Justiça (SAL/MJ) e do Programa das Nações Unidas para o Desenvolvimento (PNUD), 2010.

SAYD, J. D.; VIEIRA JUNIOR, L.; VELANDIA, I. C. "Recursos Humanos nas Conferências Nacionais de Saúde (1941 a 1992)". Rio de Janeiro, Revista Saúde Coletiva, n. 14, 1998.

SILVA, E. R. A. Participação Social e as Conferências Nacionais de Políticas Públicas: reflexões sobre avanços e desafios no período de 2003-2006. IPEA, texto para discussão no 1378, 2009.

TATAGIBA, L; TEIXEIRA, A. C. Dinâmicas participativas institucionalizadas e produção de políticas públicas. Campinas, 2008.

Viviane Petinelli - vpetinelli@hotmail.com

Recebido para publicação em março de 2010. Aprovado para publicação em abril de 2011. 